\title{
Zeolite Adsorption of Chloride from a Synthetic Alkali-Activated Cement Pore Solution
}

\author{
Jorge Osio-Norgaard ${ }^{1}$ (D) and Wil V. Srubar III 2,*(D) \\ 1 Department of Civil, Environmental, and Architectural Engineering, University of Colorado Boulder, \\ ECOT 441 UCB 428, Boulder, CO 80309-0428, USA; jorge.osionorgaard@colorado.edu \\ 2 Materials Science and Engineering Program, University of Colorado Boulder, 4001 Discovery Drive, \\ Room N378 80303, Denver CO 80309-0428, USA \\ * Correspondence: wsrubar@colorado.edu; Tel.: +1-303-492-2621
}

Received: 4 June 2019; Accepted: 20 June 2019; Published: 24 June 2019

check for updates

\begin{abstract}
This work presents experimental evidence that confirms the potential for two specific zeolites, namely chabazite and faujasite (with a cage size $\sim 2-13 \AA$ ), to adsorb small amounts of chloride from a synthetic alkali-activated cement (AAC) pore solution. Four synthetic zeolites were first exposed to a chlorinated AAC pore solution, two faujasite zeolites (i.e., FAU, X-13), chabazite (i.e., SSZ-13), and sodium-stabilized mordenite (i.e., Na-Mordenite). The mineralogy and chemical composition were subsequently investigated via X-ray diffraction (XRD) and both energy- and wavelength-dispersive X-ray spectroscopy (WDS), respectively. Upon exposure to a chlorinated AAC pore solution, FAU and SSZ-13 displayed changes to their diffraction patterns (i.e., peak shifting and broadening), characteristic of ion entrapment within zeolitic aluminosilicate frameworks. Elemental mapping with WDS confirmed the presence of small amounts of elemental chlorine. Results indicate that the chloride-bearing capacity of zeolites is likely dependent on both microstructural features (e.g., cage sizes) and chemical composition.
\end{abstract}

Keywords: alkali-activated cements; zeolite; faujasite; chabazite; chloride adsorption

\section{Introduction}

Given the worldwide prevalence of chloride-induced corrosion in reinforced concrete, the mechanisms of chloride transport and chloride binding in ordinary portland cement (OPC) paste, mortar, and concrete are generally well understood. Chlorides are transported via hydrostatic pressure, capillary absorption, and diffusion [1] and can be bound either as Friedel's salt in cement paste containing limestone or by hydrotalcite in cement paste containing dolomitic mineral phases [2]. These chloride-binding mechanisms are advantageous, given that they chemically retard the rate of chloride ingress.

Despite previous postulation that zeolites could serve a similar function in alkali-activated cements (AACs), analogous chloride-binding mechanisms in AAC paste, mortar, and concrete have not yet been reported. Zeolites, microporous aluminosilicate minerals found in a variety of low-calcium AACs rich in sodium-stabilized aluminosilicate hydrate (N-A-S-H) gels, have been suggested as prime mineral candidates for chloride adsorption, given their widespread industrial use as molecular sieves, and adsorbents for anions like $\mathrm{SO}_{4}{ }^{2-}$ and $\mathrm{PO}_{4}{ }^{3-}$ [1,3-6]. Recent evidence from Gevaudan et al. [7] and Jun et al. [8] suggest that two specific zeolites-faujasite and chabazite-have the potential to improve concrete chloride resistance (i.e., reduce bulk porosity and enhance chloride binding), thereby delaying the onset of chloride-induced corrosion. However, neither study presented experimental evidence that confirms the potential for these zeolites to physically or chemically adsorb or entrap chlorides in relevant environmental conditions. 
The aim of this work was to ascertain whether zeolite minerals commonly found in AAC cement paste, particularly faujasite (FAU), mordenite (MOR), and chabazite, (CHA) are capable of bearing free chlorides. FAU-type zeolites have been observed as reaction products in studies from 2007 to the present [7,9-12], with [7] discussing the mineralization dynamics of FAU in alkali-activated metakaolin and how the early formation of FAU can lead to a reduced permeable porosity. With regards to the presence of MOR in alkali-activated binders, precursors containing MOR, one of the most common naturally occurring zeolites [13], have been frequently activated and reported in the literature [14-21]. Due to MOR's particular reticence and poor solubility in high-pH environments [17], a portion of unreacted MOR often remains in the paste. Lastly, CHA-type zeolites have also been identified, studied, and reported in the literature [8,22]. In this study, the synthetic zeolites-two faujasite zeolites that differed only in their respective cage sizes (i.e., FAU, X-13), chabazite (SSZ-13), and sodium-stabilized mordenite (Na-Mordenite) - were exposed to a chlorinated AAC pore solution. While these synthetic zeolites are representative of those found in AAC systems, [7] demonstrated that natural zeolites in AACs systems are meta-stable, especially at early ages, and that their structure can evolve over time into more thermodynamically stable morphologies. Therefore, these synthetic zeolites were chosen to approximate the most likely stable form of these particular zeolites that have been observed to form in AACs. Zeolite mineralogy and chemical composition were subsequently investigated using X-ray diffraction (XRD) and both energy- and wavelength-dispersive X-ray spectroscopy (EDS/WDS), respectively.

\section{Materials and Methods}

\subsection{Materials}

Faujasite zeolites, FAU (cage sizes $\sim 2-13 \AA$ ) and X-13 (cage size $\sim 13 \AA$ ), were obtained from Sigma Aldrich (St. Louis, MO, USA) and Fisher Scientific (Hampton, NH, USA), respectively. Chabazite zeolites (SSZ-13) were provided by Alfa Aesar (Tewksbury, MA, USA). Na-Mordenite zeolites (MOR) were supplied by Advanced Chemical Supplier (ACS) Material. Sodium hydroxide ( $\mathrm{NaOH}$ ) pellets ( $97 \%$ purity) and powdered sodium chloride $(\mathrm{NaCl})(97 \%$ purity) were provided by Fisher Scientific (Hampton, NH, USA).

\subsection{Methods}

Using a modified version of exposure conditions found in Ke et al. [21], $1 \mathrm{~g}$ of the powdered zeolites was first exposed to $40 \mathrm{~mL}$ of the chlorinated synthetic AAC pore solution with a composition of $0.9 \mathrm{M} \mathrm{NaOH}$ and $0.1 \mathrm{M} \mathrm{NaCl}$ for 14 days under constant agitation. The pore solution composition was chosen based on previously published chloride durability studies [23-25] that emphasized the role of alkali hydroxide concentration, while stating that silica, calcium, and aluminum concentrations are typically less than $5 \mathrm{mM}$ and that their role in corrosion are negligible in comparison. Pore solution extractions from multiple AACs show that the concentration of alkali hydroxides is at least two orders of magnitude higher than other constituents [24].

Samples were then centrifuged at $4000 \mathrm{rpm}$ for $6 \mathrm{~min}$, and the supernatant was extracted. Solids were rinsed and filtered with $60 \mathrm{~mL}$ of deionized water to remove any salts that may have crystallized on the surface and allowed to dehydrate at ambient conditions.

\subsubsection{X-ray Diffraction (XRD)}

Qualitative powder XRD analysis of the control and exposed zeolite samples was performed with a Siemens D500 X-ray diffractometer (USGS, Boulder, CO, USA). Samples were analyzed from $5^{\circ}$ to $65^{\circ} 2 \theta$ using $\mathrm{Cu} \mathrm{K} \alpha$ radiation with a step size of $0.02^{\circ}$ and a $2 \mathrm{~s}$ dwell time per step. Version 9 of MDI's Jade XRD software (USGS, Boulder, USA) was used to identify changes in the control and exposed zeolite diffraction patterns [7]. 


\subsubsection{Energy- and Wavelength-Dispersive $\mathrm{X}$-ray Spectroscopy (EDS and WDS)}

Using a JEOL-8230 electron microprobe (JEOL, Tokyo, Japan), EDS was utilized to initially screen zeolites for improved chemical mapping. An acceleration voltage of $15 \mathrm{keV}$ and a beam current of $20 \mathrm{nA}$ were used to obtain spectra. With the same instrument, WDS was used to create elemental composition maps of $\mathrm{Si} \mathrm{K} \alpha, \mathrm{Na} K \alpha, \mathrm{Ca} K \alpha$, and $\mathrm{Cl} K \alpha$. For all samples, two $\mathrm{Cl} K \alpha$ maps were aggregated utilizing National Institute of Health (NIH) ImageJ software (NIH, Bethesda, MD, USA) to obtain better resolution. A similar acceleration voltage of $15 \mathrm{keV}$, a beam current of $20 \mathrm{nA}$, and a dwell time of $15 \mathrm{~ms}$ were used to obtain all maps. The electron beam was defocused to $0.5 \mu \mathrm{m}$, providing a 1:1 ratio between the beam and pixel size. The resulting maps measured approximately $500 \mu \mathrm{m}$ $\times 500 \mu \mathrm{m}$ in area. All raw data are provided in the supplementary material.

\section{Results}

\section{1. $X R D$}

Upon exposure to a chloride-laden synthetic AAC pore solution, both FAU and SSZ-13 exhibited evidence of peak broadening, shifting, and intensity reductions in comparison to their respective control diffraction patterns (Figure 1). Crystallographic theory indicates that these shifts can be due to lattice strain, due to the incorporation of ions into zeolitic aluminosilicate frameworks, which has been discussed for both cationic and anionic sorption processes of zeolite $[22,26,27]$. Therefore, the peak shifting and broadening provided an indication that these zeolites may have adsorbed free ions (e.g., $\mathrm{Na}, \mathrm{Cl}$ ) from the AAC pore solution. However, these diffraction patterns alone were insufficient to confirm whether FAU and SSZ-13 adsorbed or entrapped free $\mathrm{Cl}$ rather than $\mathrm{Na}$ (or a combination of the two) in their ionic state. X-13 (Figure 1b) and Na-Mordenite (Figure 1d) indicated little to no changes to their diffraction patterns after exposure. Of note, the diffraction pattern for Na-Mordenite was the only zeolite sample to indicate the presence of crystalline $\mathrm{NaCl}$ post-exposure.
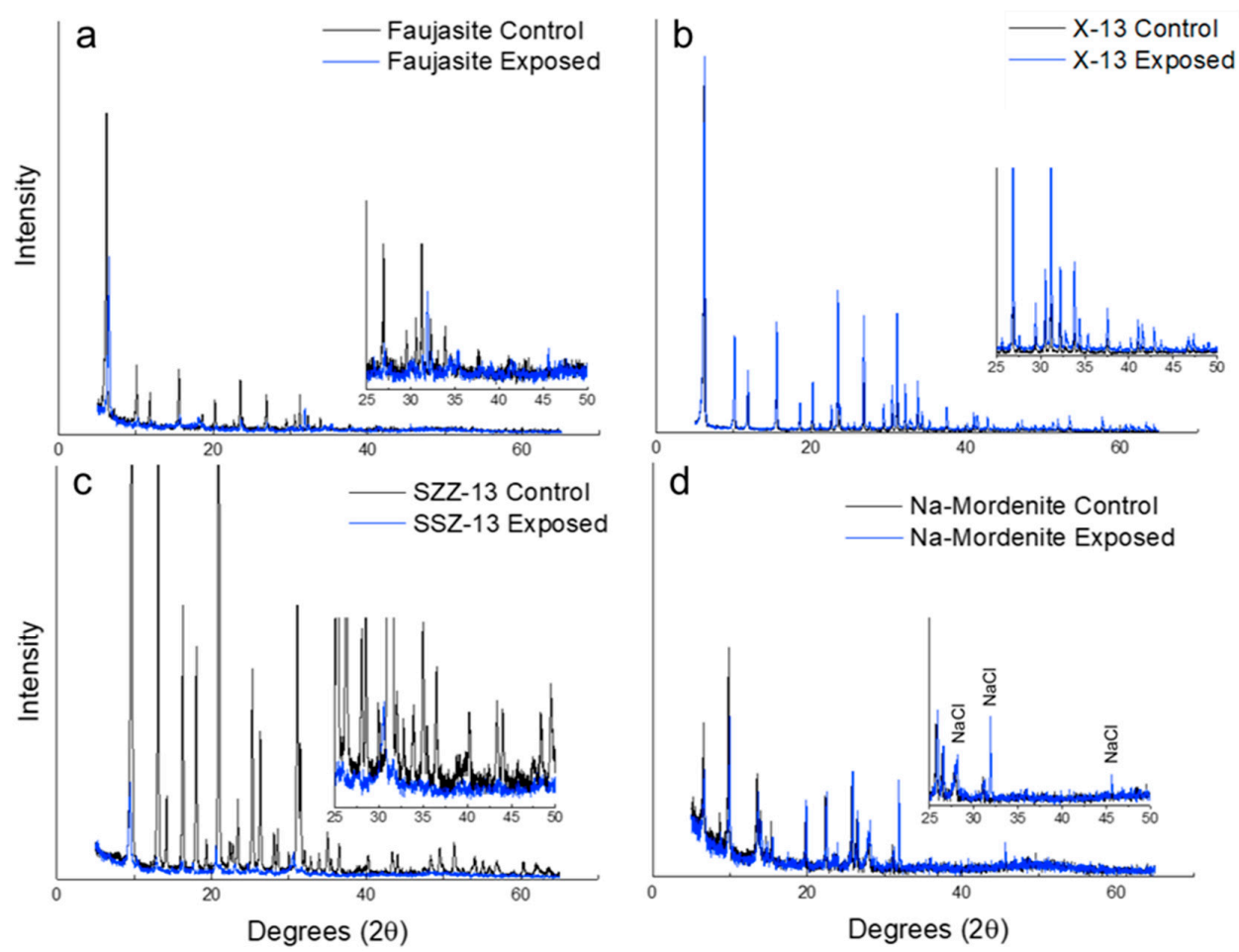

Figure 1. Diffraction patterns of (a) faujasite (FAU) (cage size $\sim 2-13 \AA$ ), (b) faujasite (X-13) (cage size $\sim 13 \AA$ ), (c) chabazite (SSZ-13), and (d) sodium-stabilized mordenite (Na-Mordenite). 


\subsection{EDS and WDS}

After confirmation via EDS that elemental chlorine was present in FAU and SSZ-13 (Table 1), WDS elemental composition maps were obtained to substantiate the presence of small amounts of free chlorides (Figure 2). Elemental composition maps for Na-Mordenite and X-13 were also generated, but yielded no presence of $\mathrm{Cl}$ higher than background levels. Figure 2a,c indicates that chloride is present in some siliceous regions (i.e., regions of high $\mathrm{Si}$ ) of FAU and SSZ-13. Silicon (Si) maps were used in this study to visualize the geometry of the aluminosilicate zeolites. The $\mathrm{Na}$ and $\mathrm{Cl}$ maps in Figure 2 suggest that small amounts of elemental chlorine are adsorbed by FAU and SSZ-13 without being bound as $\mathrm{NaCl}$, while Figure 2c does indicate the likelihood of the presence of some $\mathrm{NaCl}$ in the SSZ-13 sample. Understandably, this result could be interpreted as the formation of crystalline $\mathrm{NaCl}$ in FAU and SSZ-13. However, it is of note that both FAU and SSZ-13 zeolites also contain Na before exposure, and a significant presence of crystalline $\mathrm{NaCl}$ would be detected via XRD. The overlap between $\mathrm{Si}$ and $\mathrm{Na}$ is more prevalent and serves as an indicator that, in this instance, the $\mathrm{Na}$ is more than likely part of the original structure of the FAU and SSZ-13 zeolites.
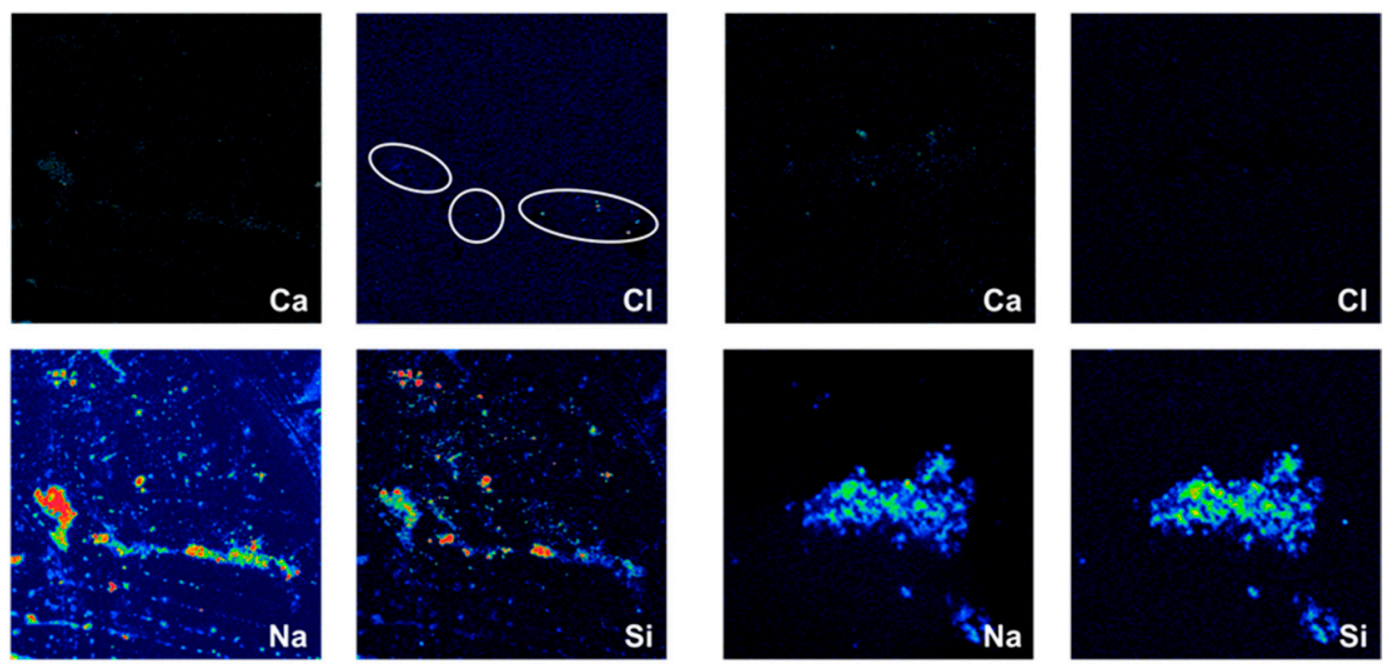

(a) Faujasite (FAU)

$\mathrm{Si}$
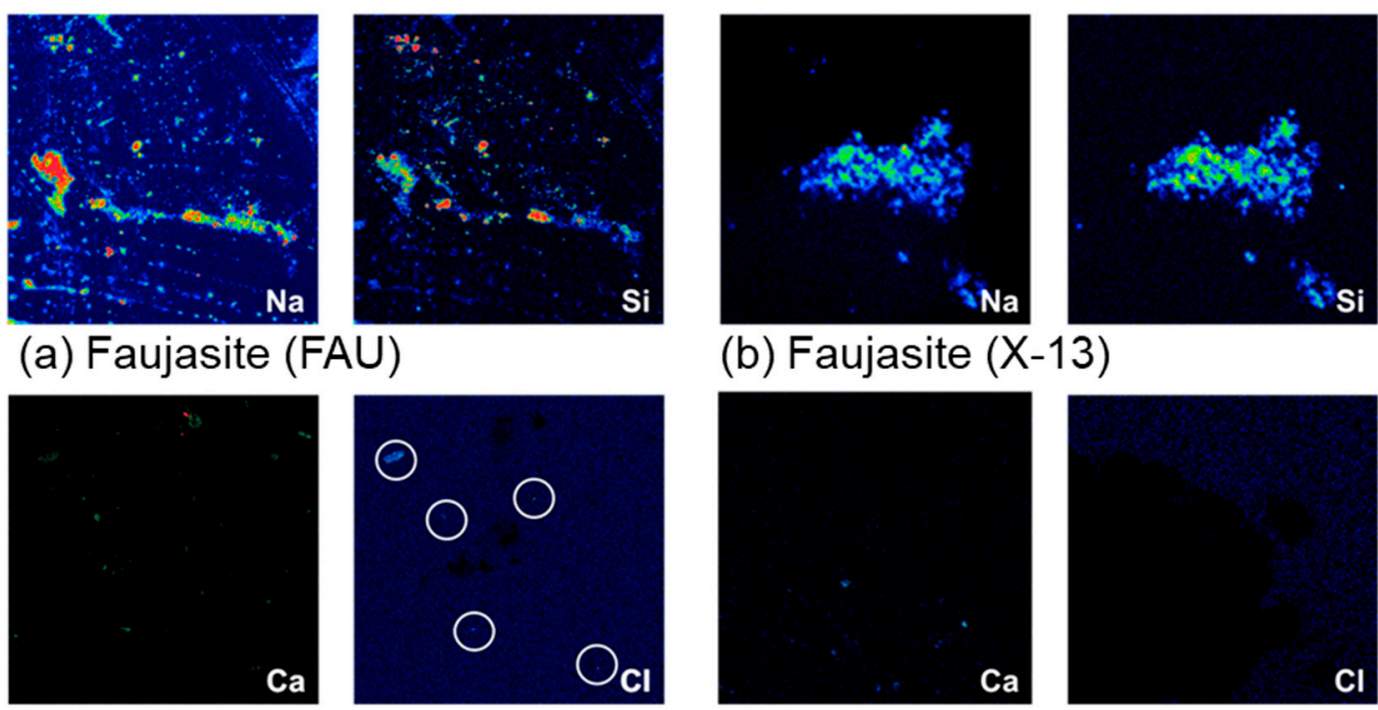

(b) Faujasite $(\mathrm{X}-13)$
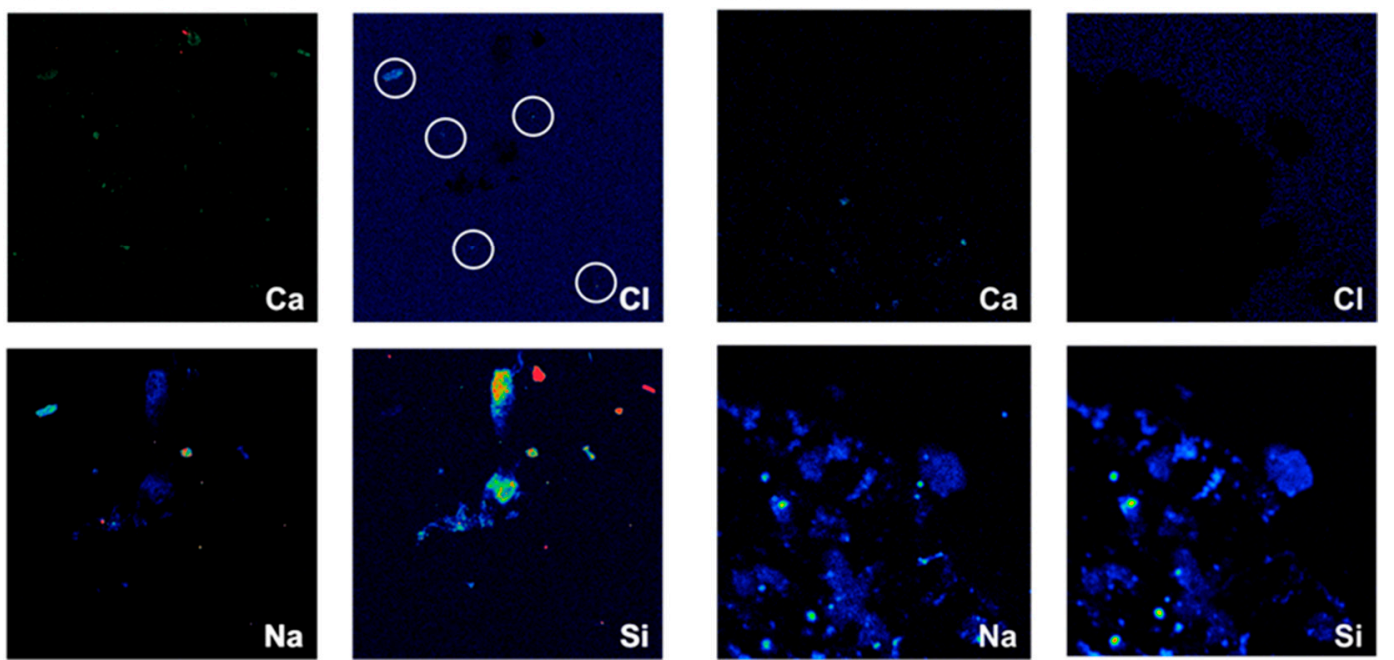

(c) Chabazite (SSZ-13)

(d) Na-Mordenite

Figure 2. WDS (wavelength-dispersive X-ray spectroscopy) elemental composition maps of chloride-exposed (a) faujasite (FAU), (b) faujasite (X-13), (c) chabazite (SSZ-13), and (d) mordenite (Na-Mordenite). 
Table 1. Summary of evidence indicating the chloride-bearing potential of zeolites.

\begin{tabular}{cccccc}
\hline Sample & Zeolite & $\begin{array}{c}\text { XRD } \\
\text { Peak Shifts or } \\
\text { Broadening }\end{array}$ & $\begin{array}{c}\text { XRD } \\
\text { NaCl Presence }\end{array}$ & $\begin{array}{c}\text { EDS } \\
\text { Chlorine } \\
\text { Presence }\end{array}$ & $\begin{array}{c}\text { WDS Chlorine } \\
\text { Presence }\end{array}$ \\
\hline FAU & Faujasite & Yes & No & Yes & Yes \\
X-13 & Faujasite & No & No & No & No \\
SSZ-13 & Chabazite & Yes & No & Yes & Yes \\
Na-Mordenite & Mordenite & No & Yes & No & No \\
\hline
\end{tabular}

\section{Discussion}

Chloride-mineral interactions (e.g., adsorption, uptake, or binding) have been widely studied in OPC and slag-based AAC systems, but the role of zeolites in chloride transport is widely unexplored [1]. $\mathrm{C}_{3} \mathrm{~A}$ in OPC systems and dolomitic minerals in slag cements have both been shown to bind non-trivial quantities of chloride ions upon exposure to chlorinated solutions [2-4]. Zeolites are structurally different (e.g., in silica content and charge) than layered double hydroxides and are primarily viewed as cation binders. However $[5,6]$ have shown that they are capable of weak anionic binding. This study is the first to directly assess the chloride uptake potential of these zeolites. While a direct comparison between the extent of chloride binding potential of zeolites versus the calcium aluminate phases in OPC could not be made in this study, future studies should aim to quantify the chloride adsorption potential of zeolites to compare them with the mineral phases in hydrated OPC [2-4].

Taken together, XRD, EDS, and WDS substantiate clear evidence that, while some zeolites are capable of bearing chloride, the capability likely depends on microstructure features, such as cage size and chemical composition. FAU and X-13-two faujasite zeolites that differ only in cage size-behaved differently in terms of their potential for chloride adsorption. X-13 has, on average, larger zeolitic cages than faujasite, which may enable chloride ions to flow through more freely. Contrastingly, SSZ-13 has a similar average cage size to $\mathrm{X}-13$ but a different chemical composition (e.g., Si:Al ratio [27]), which indicates that cage size is not the only influencing factor.

\section{Conclusions}

This work presents experimental evidence of chloride-bearing potential for two zeolites-faujasite (FAU) and chabazite (SSZ-13) - commonly found in alkali-activated cement (AAC) paste, mortar, and concrete. Results from X-ray diffraction and both energy- and wavelength dispersive X-ray spectroscopy indicate that these zeolites contain small—but non-trivial—amounts of elemental chlorine that was adsorbed from a chlorinated synthetic AAC pore solution after 14 days of exposure. Another faujasite zeolite (X-13) with a larger average cage size than FAU did not exhibit a similar potential to adsorb chlorides. Taken together, these results suggest that the chloride adsorption potential of zeolites is likely linked to both microstructural features and chemical composition. Further research is needed to elucidate and leverage the explicit chloride-uptake mechanisms in these (and other) zeolites and to quantify the extent to which chloride uptake can be enhanced. These efforts would be impactful, as they would enable the design of more chloride-resistant AAC paste, mortar, and concrete.

Supplementary Materials: The following is available online at http://www.mdpi.com/1996-1944/12/12/2019/s1: Raw Data Repository.

Author Contributions: Conceptualization, J.O.-N. and W.V.S.; methodology, J.O.-N.; formal analysis, J.O.-N.; investigation, J.O.-N.; writing-original draft preparation, J.O.-N.; writing—review and editing, J.O.-N. and W.V.S.; visualization, J.O.-N. and W.V.S.; supervision, W.V.S.; project administration, W.V.S.; funding acquisition, W.V.S.

Funding: This research was made possible by the Department of Civil, Environmental, and Architectural Engineering, the College of Engineering and Applied Sciences, the Living Materials Laboratory at the University of Colorado Boulder, and the United States National Science Foundation (Award No. CBET-1604457). 
Acknowledgments: The assistance of Kyle E. O. Foster is gratefully acknowledged, as well as Tyler Kane at the United States Geological Survey (USGS). This work represents the views of the authors and not necessarily those of the sponsors. Publication of this article was funded by the University of Colorado Boulder Libraries Open Access Fund.

Conflicts of Interest: The authors declare no conflict of interest. The funders had no role in the design of the study, in the collection, analyses, or interpretation of data, in the writing of the manuscript, or in the decision to publish the results.

\section{References}

1. Osio-Norgaard, J.; Gevaudan, J.P.; Srubar, W.V. A Review of Chloride Transport in Alkali-Activated Cement Paste, Mortar, and Concrete. Constr. Build. Mater. 2018, 186, 191-206. [CrossRef]

2. Machner, A.; Zajac, M.; Ben Haha, M.; Kjellsen, K.O.; Geiker, M.R.; De Weerdt, K. Chloride-Binding Capacity of Hydrotalcite in Cement Pastes Containing Dolomite and Metakaolin. Cem. Concr. Res. 2018, 107, 163-181. [CrossRef]

3. Birnin-Yauri, U.; Glasser, F. Friedel?S Salt, $\mathrm{Ca} 2 \mathrm{Al}(\mathrm{OH}) 6(\mathrm{Cl}, \mathrm{OH}) \cdot 2 \mathrm{H} 2 \mathrm{O}$ : Its Solid Solutions and Their Role in Chloride Binding. Cem. Concr. Res. 1998, 28, 1713-1723. [CrossRef]

4. Ke, X.; Bernal, S.A.; Provis, J. Assessing the Chloride Binding Capacity of Synthetic Cementitious Phases in Alkali- Activated Slag Simulated Pore Solution. In Proceedings of the 1st International Conference of Construction Materials for Sustainable Future, Zadar, Croatia, 19-21 April 2017.

5. Vujaković, A.D.; Tomašević-Čanović, M.R.; Daković, A.S.; Dondur, V.T. The Adsorption of Sulphate, Hydrogenchromate and Dihydrogenphosphate Anions on Surfactant-Modified Clinoptilolite. Appl. Clay Sci. 2000, 17, 265-277. [CrossRef]

6. NING, P.; BART, H.-J.; LI, B.; LU, X.; ZHANG, Y. Phosphate Removal from Wastewater by Model-La(III) Zeolite Adsorbents. J. Environ. Sci. 2008, 20, 670-674. [CrossRef]

7. Gevaudan, J.P.; Campbell, K.M.; Kane, T.J.; Shoemaker, R.K.; Srubar, W.V.; Srubar, W.V., III. Mineralization Dynamics of Metakaolin-Based Alkali-Activated Cements. Cem. Concr. Res. 2017, 94, 1-12. [CrossRef]

8. Jun, Y.; Yoon, S.; Oh, J.E. A Comparison Study for Chloride-Binding Capacity between Alkali-Activated Fly Ash and Slag in the Use of Seawater. Appl. Sci. 2017, 7, 971. [CrossRef]

9. Duxson, P.; Fernández-Jiménez, A.; Provis, J.L.; Lukey, G.C.; Palomo, A.; Van Deventer, J.S.J. Geopolymer Technology: The Current State of the Art. J. Mater. Sci. 2007, 42, 2917-2933. [CrossRef]

10. Ruiz-Santaquiteria, C.; Fernández-Jiménez, A.; Skibsted, J.; Palomo, A. Clay Reactivity: Production of Alkali Activated Cements. Appl. Clay Sci. 2013, 73, 11-16. [CrossRef]

11. Ruiz-Santaquiteria, C.; Skibsted, J.; Fernández-Jiménez, A.; Palomo, A. Alkaline Solution/Binder Ratio as a Determining Factor in the Alkaline Activation of Aluminosilicates. Cem. Concr. Res. 2012, 42, 1242-1251. [CrossRef]

12. Li, N.; Shi, C.; Wang, Q.; Zhang, Z.; Ou, Z. Composition Design and Performance of Alkali-Activated Cements. Mater. Struct. 2017, 50, 178. [CrossRef]

13. Uzal, B.; Turanli, L. Blended Cements Containing High Volume of Natural Zeolites: Properties, Hydration and Paste Microstructure. Cem. Concr. Compos. 2012, 34, 101-109. [CrossRef]

14. Xiaodong, S.; Sheng, Y.; Xuequan, W.; Mingshu, T.; Liji, Y. Immobilization of Stimulated High Level Wastes into AASC Waste Form. Cem. Concr. Res. 1994, 24, 133-138. [CrossRef]

15. Vigil de la Villa, R.; Fernández, R.; García, R.; Villar-Cociña, E.; Frías, M. Pozzolanic Activity and Alkaline Reactivity of a Mordenite-Rich Tuff. Microporous Mesoporous Mater. 2009, 126, 125-132. [CrossRef]

16. Hu, M.; Zhu, X.; Long, F. Alkali-Activated Fly Ash-Based Geopolymers with Zeolite or Bentonite as Additives. Cem. Concr. Compos. 2009, 31, 762-768. [CrossRef]

17. Rodríguez, E.D.; Bernal, S.A.; Provis, J.L.; Gehman, J.D.; Monzó, J.M.; Payá, J.; Borrachero, M.V. Geopolymers Based on Spent Catalyst Residue from a Fluid Catalytic Cracking (FCC) Process. Fuel 2013, 109, 493-502. [CrossRef]

18. Cornejo, M.H.; Elsen, J.; Togra, B.; Baykara, H.; Soriano, G.; Paredes, C. Effect of Calcium Hydroxide and Water to Solid Ratio on Compressive Strength of Mordenite-Based Geopolymer and the Evaluation of Its Thermal Transmission Property. In Materials Genetics to Structures; ASME: Pittsburgh, Pennsylvania, 2018; Volume 12, p. V012T11A022. [CrossRef] 
19. Lynch, J.L.V.; Baykara, H.; Cornejo, M.; Soriano, G.; Ulloa, N.A. Preparation, Characterization, and Determination of Mechanical and Thermal Stability of Natural Zeolite-Based Foamed Geopolymers. Constr. Build. Mater. 2018, 172, 448-456. [CrossRef]

20. Rożek, P.; Król, M.; Mozgawa, W. Geopolymer-Zeolite Composites: A Review. J. Clean. Prod. 2019, 230, 557-579. [CrossRef]

21. Ke, X.; Bernal, S.A.; Provis, J.L. Uptake of Chloride and Carbonate by Mg-Al and Ca-Al Layered Double Hydroxides in Simulated Pore Solutions of Alkali-Activated Slag Cement. Cem. Concr. Res. 2017, 100, 1-13. [CrossRef]

22. Mundra, S.; Criado, M.; Bernal, S.A.; Provis, J.L. Chloride-Induced Corrosion of Steel Rebars in Simulated Pore Solutions of Alkali-Activated Concretes. Cem. Concr. Res. 2017, 100, 385-397. [CrossRef]

23. Ke, X.; Provis, J.L.; Bernal, S.A. Structural Ordering of Aged and Hydrothermally Cured Metakaolin Based Potassium Geopolymers. In Rilem Bookseries; Springer: Dordrecht, The Netherlands, 2018; Volume 16, pp. 232-237. [CrossRef]

24. Lloyd, R.R.; Provis, J.L.; van Deventer, J.S.J. Pore Solution Composition and Alkali Diffusion in Inorganic Polymer Cement. Cem. Concr. Res. 2010, 40, 1386-1392. [CrossRef]

25. Hermassi, M.; Valderrama, C.; Moreno, N.; Font, O.; Querol, X.; Batis, N.; Cortina, J.L. Powdered Ca-Activated Zeolite for Phosphate Removal from Treated Waste-Water. J. Chem. Technol. Biotechnol. 2016, 91, 1962-1971. [CrossRef]

26. Castaldi, P.; Santona, L.; Enzo, S.; Melis, P. Sorption Processes and XRD Analysis of a Natural Zeolite Exchanged with $\mathrm{Pb} 2+, \mathrm{Cd} 2+$ and $\mathrm{Zn} 2+$ Cations. J. Hazard. Mater. 2008, 156, 428-434. [CrossRef] [PubMed]

27. Jha, B.; Singh, D.N. Fly Ash Zeolites; Springer: Singapore, 2016; Volume 78. [CrossRef]

(C) 2019 by the authors. Licensee MDPI, Basel, Switzerland. This article is an open access article distributed under the terms and conditions of the Creative Commons Attribution (CC BY) license (http://creativecommons.org/licenses/by/4.0/). 